J. Clin. Chem. Clin. Biochem.

Vol. 23. 1985. pp. $145-150$

\title{
A Specific Radioimmunoassay for the Detection of 19-Nortestosterone in Urine
}

\author{
By E. H. J. M. Jansen, R. H. van den Berg
}

Laboratory for Endocrinology

\section{G. Zomer}

Laboratory for Clinical Chemistry and Haematology and

\section{R. W. Stephany}

Laboratory for Endocrinology, National Institute of Public Health and Environmental Hygiene, Bilthoven, The Netherlands

(Received July 20/September 28, 1984)

Summary: A specific radioimmunoassay was developed for 19-nortestosterone (nandrolone) in urine.

The antisera used were raised in rabbits against a 19-nortestosterone-7 $\alpha$-carboxyethylthioether conjugate of bovine serum albumin. Tritium-labeled nortestosterone was used as tracer. Cross reactivities with metabolites of nandrolone, other anabolics and endogenous steroids were very low. To achieve additional specificity a clean up and separation procedure was developed, using isocratic high performance liquid chromatography. So far no qualitative discrepancies have been observed between the assay described here and confirmative determinations by combined high performance liquid chromatography-gas chromatography-mass spectrometry.

\section{Entwicklung eines hochspezifischen Radioimmunotests zum Nachweis von 19-Nortestosteron in Harn}

Zusammenfassung: Z̈ur Bestimmung der Konzentration von 19-Nortestosteron (Nandrolon) im Harn wurde ein spezifischer Radioimmunotest entwickelt.

Dazu wurden gegen 19-Nortestosteron-7 $\alpha$-carboxyethylthioether-Konjugat mit Rinderserumalbumin in Kaninchen erzeugte Antiseren und Tritium-markiertes Nortestosteron verwendet. Die Antiseren zeigten sehr geringe Kreuzreaktionen gegenüber Nortestosteronmetaboliten, sonstigen Anabolika und körpereigene Steroide. Zur weiteren Erhöhung der Spezifität wurde ein isokratischer hochleistungsflüssigkeitschromatographischer Reinigungs- und Trennungsschritt vorangestellt.

Bisher wurden noch keine qualitativen Diskrepanzen zwischen den Ergebnissen der hier beschriebenen Methode und den Kontrolluntersuchungen mittels kombinierter HochleistungsflüssigkeitschromatographieGaschromatographie-Massenspektrometrie beobachtet.

\section{Introduction}

The use of hormonal anabolic agents in animal production can increase protein deposition and nitrogen retention, resulting in a $10-15 \%$ increase in weight, particularly in cattle. Especially diethylstilbestrol, a so-called stilbene oestrogen, is widely used on account of its cheapness, stability and efficacy. Since the reintroduction in the Netherlands of the forensic control programme for "stilbenes" in bovine urine the use of diethylstilbestrol has decreased dramatically to almost zero (1). 
This trend was observed earlier in an investigation of anabolic preparations detected in application sites isolated from slaughtered cattle (2). The frequency of detection indicated that diethylstilbestrol was present in only $11 \%$ of the preparations investigated, whereas 19-nortestosterone, medroxyprogesterone and testosterone in combination with oestradiol were found much more frequently. Especially 19-nortestosterone was detected in almost all (97\%) of the anabolic preparations.

In our Institute these observations have initiated on behalf of the Veterinary Chief Inspectorate of the Ministry of Public Health the development of several detection methods for 19-nortestosterone in urine. Although it is known from the literature that 19nortestosterone is metabolized to a large extent in human, rabbit and horse, it was still decided, for forensic purposes, to develop methods for 19-nortestosterone itself, with a view to a metabolic study of 19-nortestosterone laurate in cattle. Besides the development of thin layer chromatography and high resolution mass spectrometry, a radioimmunoassay was required for large scale detection of 19-nortestosterone residues in bovine urine. Since no commercial antiserum against 19-nortestosterone was available, own antisera were produced in rabbits. To obtain a better specificity than reported in the literature $(8-11)$ an albumin conjugate was synthesized attached at position 7 of the steroid moiety. In addition an immunoassay was developed using. chemiluminescence detection (16). To obtain the additional specificity required for forensic investigations, the urine extracts were purified using high performance liquid chromatography (HPLC) prior to the immunoassays. The characteristics of the antiserum and the HPLC-RIA are reported here, and their application to the radioimmunochemical detection of 19-nortestosterone in bovine urine is described.

\section{Material and Methods}

Reagents

All solvents and reagents used were analytically pure. The enzyme preparation glucuronidase/sulphatase (Suc d'Helix pomatia) was obtained from IBF Reactifs, France and used without further purification.

Tritiated 19-nortestosterone (19-[6,7(n)- $\left.{ }^{3} \mathrm{H}\right]$ nortestosterone, TRQ $2510,703 \mathrm{GBq} / \mathrm{mmol}=19 \mathrm{Ci} / \mathrm{mmol}$ ) was obtained from the Radiochemical Centre, Amersham, England.

Bovine serum albumin (BSA) was obtained from Sigma.

The steroid standards 19-nortestosterone, 19-norepitestosterone, $5 \beta$-oestrane- $3 \alpha, 17 \beta$-diol, $5 \beta$ =oestrane-3 $\beta, 17 \beta$-diol, 19norandrostenedione, 19-norandrostanedione, 19-noretiocholanolone were kindly supplied by $H$.A.E. Kuys, Organon Scientific Group, Oss, the Netherlands. $17 \alpha$ - and $17 \beta$-trenbolone were kindly supplied by Dr. J.C. Bouffault, RousselUclaf, France. Other steroids were obtained from various commercial sources and checked for purity with HPLC, UVand IR-spectroscopy. RIA buffer consisted of $0.1 \mathrm{~mol} / \mathrm{l}$ phosphate buffered saline ( $\mathrm{pH} 7.0$ ) to which $0.5 \mathrm{~g}$ gelatin per liter was added.

Preparation of 19-nortestosterone-BSA conjugate (fig. 1)

A solution of 19-nortestosterone $(1.0 \mathrm{~g})$, trimethoxymethane $(1 \mathrm{ml})$ and $p$-toluene sulphonic acid $(100 \mathrm{mg})$ in dioxane $(10 \mathrm{ml})$ was left at room temperature for two hours. Water $(10 \mathrm{ml})$ and pyridine $(1 \mathrm{ml})$ were added and the mixture was extracted with chloroform $(3 \times 50 \mathrm{ml})$. The combined organic layers were dried over sodium sulphate and evaporated to give the dienol ether. The 17-hydroxyl group was partly formylated under these conditions. Part of the crude product $(100 \mathrm{mg})$ was dissolved in $10 \mathrm{ml}$ acetone/water $(95+5)$. Dichlorodicyanoquinone (DDQ, $80 \mathrm{mg})$ dissolved in acetone $(2 \mathrm{ml})$ was added. After two minutes at room temperature more acetone $(20 \mathrm{ml})$ was added and the mixture was filtered over alumina $(10 \mathrm{~g})$. Elution with pure acetone gave the dienone. The ester function was hydrolysed by the action of $0.1 \mathrm{~mol} / \mathrm{l}$ sodium hydroxide in water/methanol $(1+1)$. The crude product was purified by flash chromatography. Elution with petroleum ether (b.p. $40-60^{\circ} \mathrm{C}$ )/ ethyl acetate $(1+1)$ afforded pure oestra-4,6-diene-3-one-17 $\beta$ ol. Proton magnetic resonance chemical shifts in ppm relative to tetramethylsilane in deuterochloroform were $8.82(\mathrm{~s}, 3 \mathrm{H})$, $3.67(\mathrm{bt}, 1 \mathrm{H}), 5.72(\mathrm{bs}, 1 \mathrm{H}), 6.13(\mathrm{~s}, 2 \mathrm{H})$.

The $7 \alpha$-carboxyethyl thio ether of nortestosterone was prepared according to the method described by Weinstein et al. (3).

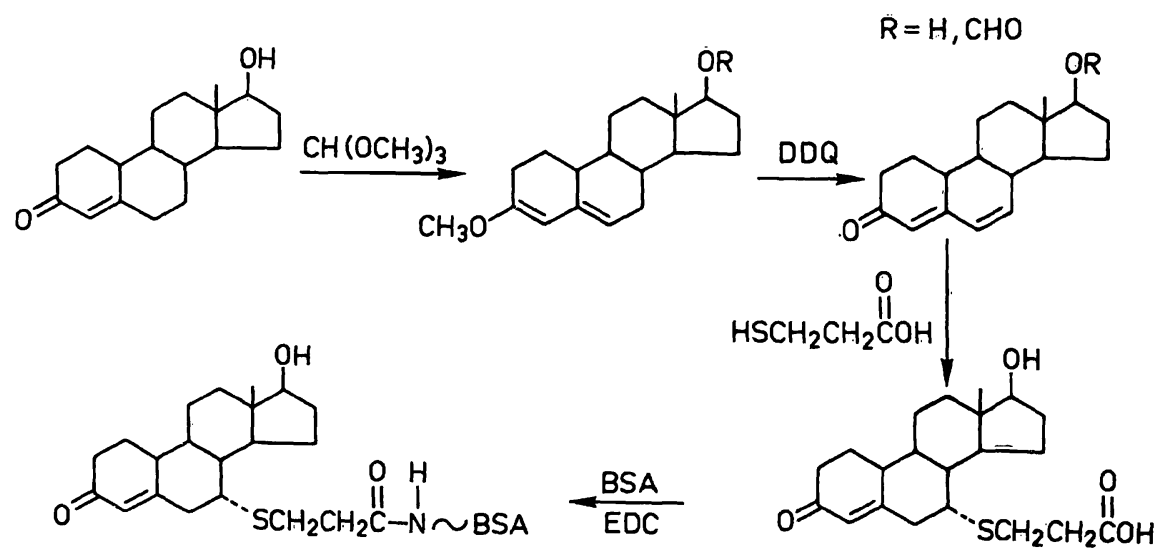

Fig. 1. Reaction scheme for the synthesis of the 19-nortestosterone-7 $\alpha$-carboxyethylthioether conjugate of bovine serum albumin (BSA). $\mathrm{DDQ}=$ Dichlorodicyanoquinone $\mathrm{EDC}=\mathrm{N}$-ethyl-N'(3-dimethylaminopropyl)-carbodiimide $;$ 
The conjugation of the nortestosterone thio ether to bovine serum albumin was accomplished using the carbodiimide method (4).

\section{Preparation of antisera against 19-nortestosterone- BSA}

Antisera against the 19-nortestosterone-BSA conjugate were raised in rabbits (New Zealand) by four intramuscular injections of $0.5 \mathrm{mg}$ immunogen dissolved in $0.3 \mathrm{ml}$ saline and $0.7 \mathrm{ml}$ complete Freund's adjuvant at 4 week intervals. After each booster injection the antiserum titer was checked.

\section{HPLC purification of urine extracts}

The HPLC equipment included an automatic injector (WISP, Water Ass.), and two solvent delivery sytems (model M45 and $6000 \mathrm{~A}$, Water Ass.) controlled by a system controller (Waters Ass.) (fig. 2). UV absorption was monitored at $240 \mathrm{~nm}$ with a variable wavelength detector (model 450, Waters Ass.). The HPLC-column (150 $\mathrm{mm} \times 4.6 \mathrm{~mm}$, Chrompack) was packed with Hypersil ODS, $5 \mu \mathrm{m}$ (Shandon) using a Column Packing Instrument (Shandon) and was protected by a precolumn (75 $\mathrm{mm} \times 2.1 \mathrm{~mm}$, Chrompack) filled with Bondapak Corasil C18 (Waters Ass.). The main column was thermostated at $30^{\circ} \mathrm{C}$ with a home-made metal heat exchanger. Flow conditions were from 0 to $7 \mathrm{~min}$ methanol/water $(6+4)$ and from 7 to $9 \mathrm{~min}$ pure methanol at a flow rate of $2.0 \mathrm{ml} / \mathrm{min}$.

After addition of $150 \mathrm{pg}$ tritiated 19-nortestosterone as a recovery tracer to $1 \mathrm{ml}$ urine, followed by enzymatic hydrolysis and ether extraction, an aliquot of $0.4 \mathrm{ml}$ urine was applied onto the HPLC-column. The 19-nortestosterone fraction was collected automatically during 1 minute around the retention time of 19-nortestosterone, which was determined previously from the UV absorption ( $240 \mathrm{~nm}$ ) of a 19-nortestosterone standard (40 ng). The fraction collecting system consisted of a modified fraction collector (model Redirac, LKB) equipped with Hypersil ODS, $5 \mu \mathrm{m}$ (Shandon) using a Column Packing Instrument (Shandon) and was protected by a precolumn (75 $\mathrm{mm} \times 2.1 \mathrm{~mm}$; Chrompack) filled with Bondapak Corasil C18 (Waters Ass.). The main column was thermostated at $30^{\circ} \mathrm{C}$ with a home-made metal heat exchanger. Flow conditions were from 0 to $7 \mathrm{~min}$ methanol/water $(6+4)$ and from 7 to $9 \mathrm{~min}$ pure methanol at a flow rate of $2.0 \mathrm{ml} / \mathrm{min}$.

\section{Radioimmunoassay procedure}

The 19-nortestosterone fraction from the HPLC-eluate was evaporated at $60^{\circ} \mathrm{C}$ under nitrogen. To the dry residue $1 \mathrm{ml}$ of RIA buffer was added. From this solution $0.300 \mathrm{ml}$ was used for determination of the recovery and $2 \times 0.300 \mathrm{ml}$ was used in the RIA procedure in duplicate. After addition of $0.050 \mathrm{ml}$ RIA-tracer $\left(\left[{ }^{3} \mathrm{H}\right] 19\right.$-nortestosterone, 8000 counts $\left./ \mathrm{min}\right), 0.050 \mathrm{ml}$ antiserum and $0.100 \mathrm{ml}$ RIA buffer, the RIA mixture was incubated for 1 hour at $4^{\circ} \mathrm{C}$. Separation of bound and free steroid was accomplished by centrifugation after addition of dextran coated charcoal. Counting of radioactivity was performed on the bound fraction.

The results were calculated from a calibration curve derived from enriched blank urine samples which were submitted to the same purification procedure. The calibration line was calculated after logit-log transformation and linear regression analysis according to Rodbard \& Lewald (13). A schematic representation of the whole procedure is shown in the nowdiagram.

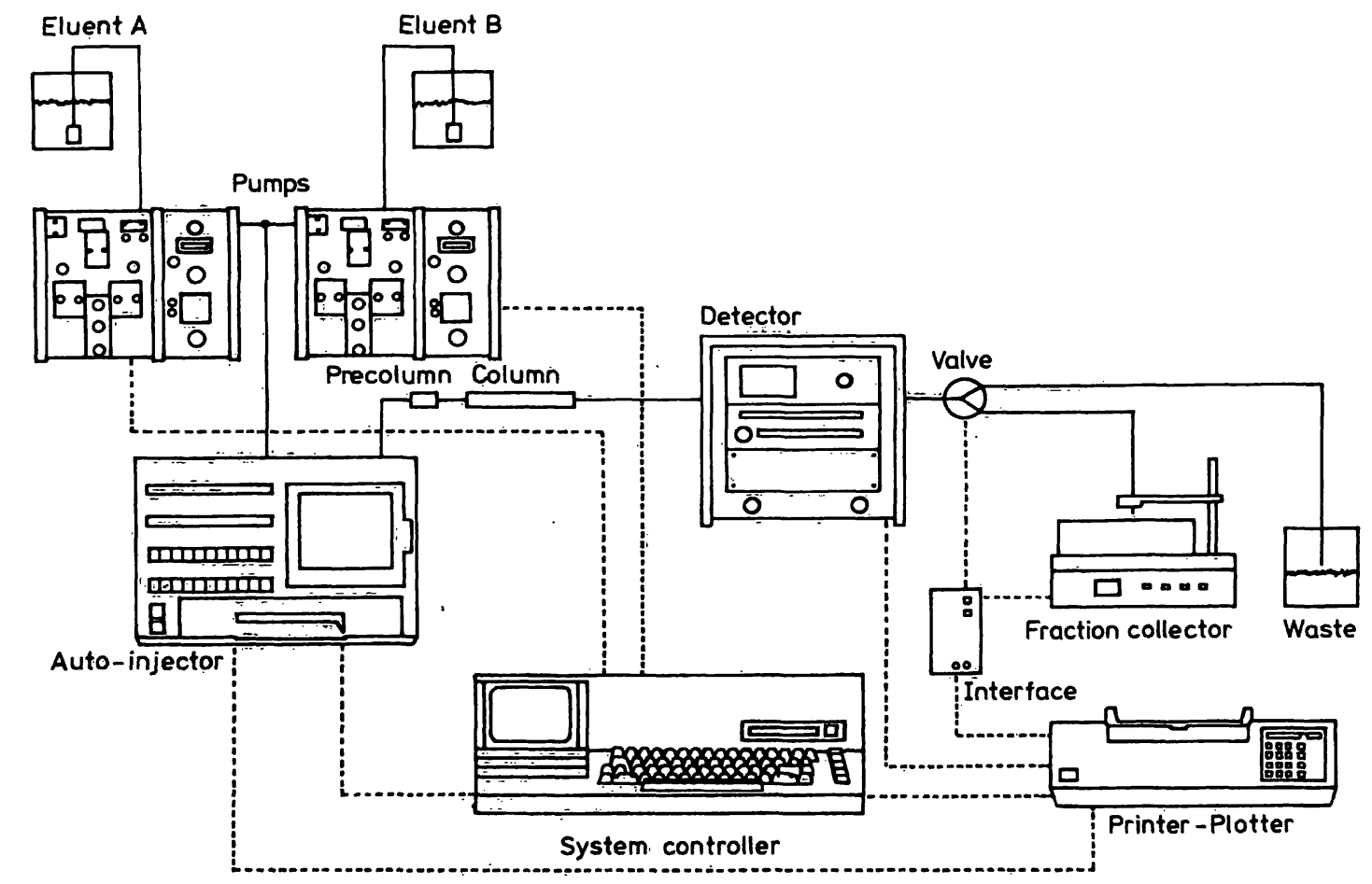

Fig. 2. HPLC equipment for the purification of urine extracts prior to the RIA for 19-nortestosterone. solvent line

electrical (data) line 
Flow-diagram of the HPLC-RIA procedure for determination of 19-nortestosterone in urine.

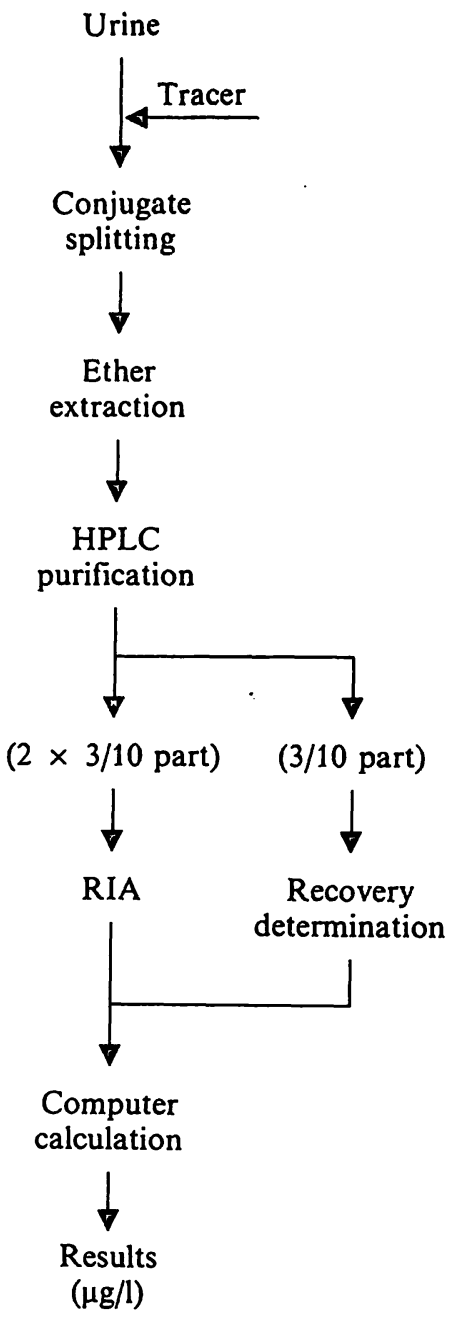

\section{Results}

\section{HPLC-purification}

Application of the RIA directly to the ether extract of the urine sample, can lead to interference by cross reacting compounds. Therefore an isocratic HPLC purification was developed, in which the steroids trenbolone, 19-nortestosterone, oestradiol and testosterone were completely separated from each other (fig. 3). The isocratic HPLC purification was automated using an auto-injector and only the 19-nortestosterone fraction was collected using an automatic fraction collecting system developed at our laboratory. In this configuration 48 urine extracts can be purified automatically overnight ( 15 hours). This purification system has been operated very satisfactorily in the purification and separation of various anabolics prior to RIA, TLC or GC/MS (6) and in the radioimmunogram method used for the identification of the stilbene derivatives (7).

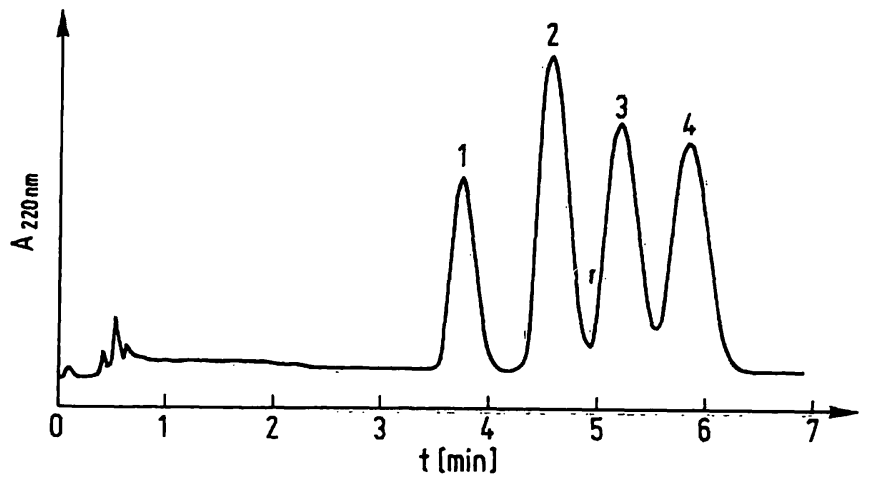

Fig. 3. HPLC-chromatogram on Hypersil ODS of a standard mixture of trenbolone (1), 19-nortestosterone (2), oestradiol (3) and testosterone (4). Experimental condition: from 0 to $7 \mathrm{~min}$ methanol/water $(6+4)$ and from 7 to $9 \mathrm{~min}$ pure methanol at a flow of $2.0 \mathrm{ml} / \mathrm{min}$.

\section{Specificity of antisera}

Cross-reactivities of two antisera towards possible metabolites and related (anabolic) steroids are given in table 1. Both antisera showed comparable specificity. The cross-reactivities were calculated according to Abraham (5).

Only $17 \beta$-trenbolone showed an appreciable (9.3\%) cross-reactivity. All other related steroids, including testosterone and oestradiol, showed cross-reactivities of less than $1.7 \%$.

The antiserum dilutions used were rather low, $1: 3000$ and $1: 800$. This is partly due: to the low specific radioactivity of the label. The respective relative maximum binding was 30 and $26 \%$.

\section{Assay parameters}

To calculate the intra- and inter-assay variation, the 19-nortestosterone content of three urine samples (female calves of 14 weeks) was determined ten times in four independent assays. The quality control parameters of the RIA are summarized in table 2 . In these samples the presence of 19-nortestosterone was confirmed by HPLC-GC/MS with high resolution MS by peak matching of the methoximetrimethylsilylether derivative of 19-nortestosterone with a mass of $375.2593 \pm 0.0015$ atomic mass units.

The assay parameters summarized over four assays are (mean \pm s.d.): initial binding (b/T) $42.5 \% \pm$ $4.9 \%$; nonspecific binding $(\mathrm{a} / \mathrm{T}) \quad 0.8 \% \pm 1.4 \%$; correlation coefficient $0.991 \pm 0.006$; slope $0.924 \pm$ 0.081 ; sensitivity at $50 \%$ binding $230 \mathrm{pg} \pm 24 \mathrm{pg}$ per tube and at $90 \%$ binding $21.7 \mathrm{pg} \pm 6.2 \mathrm{pg}$ per tụbe. 
Tab. 1. Relative cross-reactivities of two antisera (H 152460 and H 152461) against 19-nortestosterone as determined according to Abraham (5) and expressed as percentages.

\begin{tabular}{|c|c|c|}
\hline Chemical (trivial) name & $\begin{array}{l}\text { H } 152460 \\
\text { diluted } \\
1: 3000\end{array}$ & $\begin{array}{l}\text { H } 152461 \\
\text { diluted } \\
1: 800\end{array}$ \\
\hline 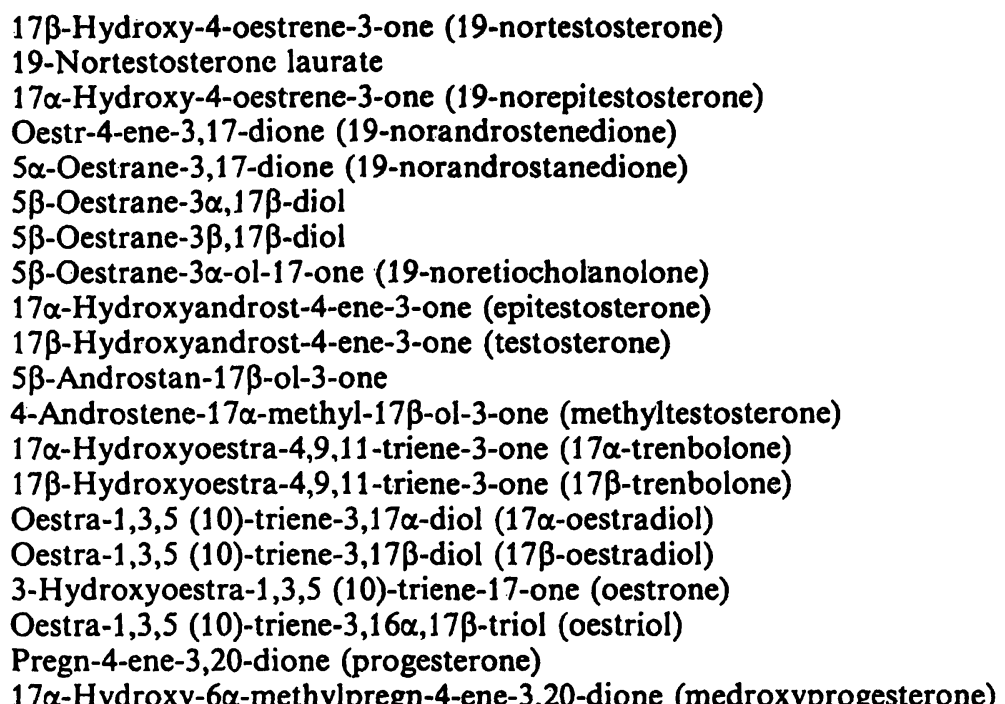 & $\begin{array}{l}100 \\
0.09 \\
0.4 \\
0.3 \\
0.5 \\
0.06 \\
0.08 \\
0.03 \\
<0.01 \\
<0.05 \\
<0.01 \\
<0.01 \\
<0.01 \\
9.2 \\
0.1 \\
1.6 \\
0.3 \\
0.4 \\
0.02 \\
0.1\end{array}$ & $\begin{array}{c}100 \\
0.4 \\
0.5 \\
0.1 \\
0.2 \\
0.04 \\
0.2 \\
0.02 \\
<0.01 \\
1.7 \\
<0.01 \\
<0.01 \\
<0.01 \\
9.3 \\
0.01 \\
0.6 \\
0.07 \\
0.4 \\
0.02 \\
0.9\end{array}$ \\
\hline
\end{tabular}

Tab. 2. Quality control parameters of the 19-nortestosterone RIA after HPLC purification

\begin{tabular}{|c|c|c|c|}
\hline \multirow{2}{*}{$\begin{array}{l}\text { Code of } \\
\text { urine } \\
\text { sample }\end{array}$} & \multirow{2}{*}{$\begin{array}{l}\text { 19-nortestosterone } \\
\overline{\mathrm{x}} \pm \mathrm{s} . \mathrm{d} \\
(\mathrm{N}=40) \\
(\mu \mathrm{g} / \mathrm{l})\end{array}$} & \multicolumn{2}{|l|}{ C.V. $\left.(\%)^{*}\right)$} \\
\hline & & $\begin{array}{l}\text { intra-assay } \\
(N=10)\end{array}$ & $\begin{array}{l}\text { inter-assay } \\
(\mathrm{N}=4)\end{array}$ \\
\hline H 152734 & $0.91 \pm 0.10$ & 7.6 & 17.9 \\
\hline H 152732 & $1.38 \pm 0.12$ & 6.3 & 11.3 \\
\hline H 152735 & $5.72 \pm 0.36$ & 4.5 & 12.0 \\
\hline
\end{tabular}

*) For duplicate determinations.

The calculations were performed according to McDonagh et al. (12).

$\bar{x}$ mean; s.d. standard deviation; $N$ number of measurements; C.V. coefficient of variation.

The overall recovery of 19-nortestosterone from urine to RIA buffer was $97.0 \% \pm 6.0 \%$ (s.d.), as determined in 318 samples of bovine urine with tritiated 19-nortestosterone $(150 \mathrm{pg})$. The recovery of tritiated 19-nortestosterone was independent of the amount of urinary 19-nortestosterone in the range of 0 to $25 \mu \mathrm{g} / 1$.

\section{Discussion}

To obtain a specific antiserum against 19-nortestosterone both the stereochemical configuration and electronic structure at the 3,17 and 19 positions should remain unchanged. Therefore, coupling of 19nortestosterone to bovine serum albumin was accomplished via a thio ether linkage at the C-7 position. Indeed specific antisera with very low crossreactivities $(\leqq 1.7 \%)$ towards metabolites of 19 -nortestosterone and naturally occurring steroids were observed. The highest cross-reactivity found so far $(9.3 \%)$ was for trenbolone, a xenobiotic anabolic steroid. In view of the similar molecular structures of trenbolone and 19-nortestosterone, a substantial cross reactivity was to be expected, especially since trenbolone also lacks the 19-methyl group.

All antisera used in radioimmunoassays of 19-nortestosterone described in the literature were raised against 3 -carboxymethyloxime $(8,11), 17-\beta$-hemisuccinate (11) or $11 \alpha$-hydroxyhemisuccinate (8) 19nortestosterone-BSA conjugates. Consequently these antisera showed substantial cross-reactivities against various other steroids.

The 19-nortestosterone RIA described in this paper will be applied mainly to the screening of cattle urine to monitor the illegal use of 19-nortestosterone. So far no significant immunochemical response for 19nortestosterone $(\leqq 0.3 \mu \mathrm{g} / \mathrm{l})$ has been observed with samples of urine from untreated cattle. To avoid problems associated with false positive results (1) a highly specific RIA is required. Confirmation by final identification must be performed by HPLC-GC/MS. 
Possible false positive results can be caused by trenbolone, oestradiol and testosterone. Although the latter two compounds show low cross-reactivities for both antisera, the high concentration of these naturally occurring and endogeneous steroids can cause positive responses in the RIA determinative step. A comparative investigation of the RIA without prior chromatographic purification (direct-RIA) and the HPLC-RIA with 32 urine samples from suspected animals showed that, without HPLC-purification, the apparent 19-nortestosterone concentrations were 1.7 times higher, probably due to the endogenous concentrations of oestradiol and testosterone. For this reason a separation procedure was developed for 19nortestosterone, trenbolone, oestradiol and testosterone, using isocratic HPLC. The HPLC-purification, in which only the 19-nortestosterone fraction is collected, is completely automated including the fraction collecting system. Recently a purification on a celite column was reported (8), which may also be suitable. Fơr further experiments, our antiserum H 152460 will be used on account of its higher titer and negligible cross-reactivity with testosterone. On the basis of the specificity of the developed antisera and the assay characteristics, such as recovery, intraand inter-assay variation, it can be concluded that the radioimmunoassay for 19 -nortestosterone as described in this paper is suitable as a reliable screening method for forensic purposes.

At the present time the detection of 19-nortestosterone as such is mandatory because 19-nortestosterone is a xenobiotic steroid. Since it can be expected $(9,10,11,14,15)$ that both 19-nortestosterone and testosterone will be metabolized rapidly to a variety of metabolites, residual amounts of the parent compound in urine will be very low. Work is in progress on 19-nortestosterone metabolism in cattle in order to find a suitable, more abundant metabolite as an indicator of the use of 19nortestosterone and its esters.

\section{Acknowledgement}

This work was performed within projects 368301,368303 and 378303 on behalf and for the account of the Dutch Veterinary Chief Inspectorate of Public Health.

The experimental assistance of $\boldsymbol{R}$. Both-Miedema (HPLC), $C$. Enkelaar-Willemsen (RIA), P.W. Zoontjes (antisera) and J.J. van de Siepkamp (antisera) is acknowledged.

The GC/MS measurements were performed within the Section Spectrometry (Head Dr. J. Freudenthal) of our Institute.

\section{References}

1. Jansen, E. H. J. M. \& Stephany, R. W. (1985) Vet. Quart. $7,35-38$.

2. Jansen, E. H. J. M., Van Blitterswijk, H. \& Stephany, R.W. (1984) Vet. Quart. 6, 60-65.

3. Weinstein, A., Lidner, H. R., Friedlander, A. \& Bauminger, S. (1972) Steroids $20,789-812$.

4. Kurzer, F. \& Dourahghi-Zadeh, K. (1967) Chem. Reviews $67,107-152$.

5. Abraham, G.E. (1969) J. Clin. Endocrinol. Metab. 29, $866-870$.

6. Jansen, E.H.J.M., Both-Miedema, R., Van Blitterswijk, H. \& Stephany, R. W. (1984) J. Chromatogr. 299, 450-455.

7. Jansen, E. H.J.M., Van den Berg, R. H., Van Blitterswijk, H., Both-Miedema, R. \& Stephany, R.W. (1984) Vet. Quart. 6, 5-7.

8. Bosch, A. M. G. (1984) J. Clin. Chem. Clin. Biochem. 22, $29-34$.
9. Jondorf, W.R. \& Moss, M.S. (1978) Xenobiotica 8, 197-206.

10. Jondorf, W. R. (1977) Xenobiotica 7, 671-681.

11. Hampl, R., Picha, J., Chundela, B. \& Starka, L. (1979) J. Clin. Chem. Clin. Biochem. 17, 529-532.

12. McDonagh, B.F., Munson, P.J. \& Rodbard, D. (1977) Comp. Prog. in Biomed. 7, 179-190.

13. Rodbard, D. \& Lewald, J.E. (1970) Acta Endocrinol., Suppl. 147, 79-103.

14. Both-Miedema, R., Van Groenestein, T.J.A., De Groot, W.C., Huis in 't Veld, L. G., Rijsdijk, J.C.J.M. \& Stekelenburg, P. (1972) Steroids Lipids Res 3, 49-58.

15. Courtot, D., Forichon, J. \& Paris, J. (1983) Chromatography in Biochemistry, Medicine and Environmental Research, (Frigerio, A., ed.) Elsevier, Amsterdam, pp. 95-110.

16. Jansen, E.H.J.M., Zomer, G., Van den Berg, R.H. \& Stephany, R.W. (1984) Vet. Quart. 6, 101-103.

Dr. Ir. E. H. J. M. Jansen

Laboratory for Endocrinology

National Institute of Public

Health and Environmental Hygiene

P. O. Box 1

NL-3720 BA Bilthoven 